\title{
Relationship Between Depression and Quality of Life Among Vitiligo Patients: A Self-assessment Questionnaire-based Study
}

This article was published in the following Dove Press journal: Clinical, Cosmetic and Investigational Dermatology

\author{
Narumol Silpa-archa (D) \\ Chutipon Pruksaeakanan (D' \\ Nattha Angkoolpakdeekul (iD) ${ }^{2}$ \\ Chayada Chaiyabutr (D) \\ Kanokvalai Kulthanan (D) \\ Woraphat Ratta-apha $\mathbb{D D}^{3}$ \\ Chanisada Wongpraparut (iD) \\ 'Department of Dermatology, Faculty of \\ Medicine Siriraj Hospital, Mahidol \\ University, Bangkok, Thailand; ${ }^{2}$ Faculty of \\ Medicine Siriraj Hospital, Mahidol \\ University, Bangkok, Thailand; \\ ${ }^{3}$ Department of Psychiatry, Faculty of \\ Medicine Siriraj Hospital, Mahidol \\ University, Bangkok, Thailand
}

Background: Vitiligo is a common chronic autoimmune disease that is characterized by progressive loss of skin color due to melanocyte destruction. In addition to the physical effects of vitiligo, this condition exerts adverse psychological effects and causes social stigmatization. Earlier studies reported that individuals with vitiligo suffer from poor quality of life (QoL), but data about the QoL of Thai vitiligo patients is scarce.

Objective: This study aimed to investigate the QoL and prevalence of depression in Thai vitiligo patients, association between QoL and depression, and factors associated with QoL and depression among Thai people with vitiligo.

Methods: This cross-sectional self-assessment questionnaire-based study was conducted at the phototherapy and vitiligo clinics of the Department of Dermatology, Faculty of Medicine Siriraj Hospital, Mahidol University (Bangkok, Thailand). QoL was assessed using the Dermatology Life Quality Index (DLQI) questionnaire, and depression was evaluated via the Patient Health Questionnaire (PHQ-9).

Results: Among the 104 vitiligo patients that were recruited, the mean DLQI score was 7.46, and the prevalence of depression (PHQ-9 $\geq 9$ ) was $13.5 \%$. Factors significantly associated with a higher mean DLQI score were skin phototype IV compared to phototype III, active disease, new lesions within the last three months, lesions involving upper extremities, and PHQ-9 $\geq 9 \quad(p<0.05)$. Moderate correlation was found between DLQI score and PHQ-9 score (Pearson's correlation coefficient: $0.524, p<0.001$ ). Factors significantly associated with depression were working status and developing new lesions within the last three months $(p<0.05)$. Patients with new lesions were 4.12 times more likely to be depressed than those without new lesions (OR: 4.12, 95\%CI: 1.20-14.16; $p=0.025$ ).

Conclusion: Developing new lesions, active disease, dark skin phototype (IV), and lesion on upper extremity had significant adverse effects on QoL. Vitiligo patients who were employed and who had new vitiligo lesions are significantly more likely to be depressed.

Keywords: relationship, depression, quality of life, QoL, vitiligo patients, self-assessment questionnaire-based study, Thailand

\section{Introduction}

Vitiligo is a common chronic autoimmune disease that is characterized by progressive loss of skin color due to melanocyte destruction. The worldwide prevalence of vitiligo in adults ranges from $1-2 \%{ }^{1}$ The pathogenesis of vitiligo is multifactorial, and includes autoimmune, genetic, and environmental factors. ${ }^{2}$ In addition to the physical effects of vitiligo, this condition exerts adverse psychological effects and causes social stigmatization. $^{3}$ Moreover, the effects of vitiligo may be more pronounced among
Wongpraparut

Department of Dermatology, Faculty of Medicine Siriraj Hospital, Mahidol

University, 2 Wanglang Road, Bangkoknoi, Bangkok 10700, Thailand

Tel +66 2-419-4333

Fax +66 2-4II-503।

Email chanisada@hotmail.com 
people with darker skin due to the greater contrast between their normal skin color and their white-colored depigmented lesions. The understanding and acceptance of vitiligo may vary among cultures, with greater adverse effect on marriage and family relationships in less accepting cultures. The resulting stress that is caused by these factors unfavorably influences quality of life (QoL) and increases the likelihood of the development of psychosocial problems. The global Dermatology Life Quality Index (DLQI) scores of vitiligo patients vary among countries, and previous studies reported more QoL impairment in woman than men, in young patients compared to older aged patients, in dark-skinned patients compared to white patients, in married women with vitiligo than in single women, and in patients with involvement on exposed sites than in those with lesions at areas that are less visible. ${ }^{4}$ Earlier studies reported that vitiligo has a greater impact on the QoL of Asians than on the QoL of Caucasians. The mean DLQI scores of vitiligo in India ${ }^{5}(10.67)$ and Saudi Arabia $^{6}$ (9.0) were higher than those of vitiligo in the USA ${ }^{7}$ (5.9) and Belgium ${ }^{8}$ (4.95).

The psychological problems that can occur in vitiligo include depression, anxiety, obsessive compulsive disorder, and suicidal thoughts. ${ }^{9-11}$ A meta-analysis conducted by Wang et al, found that vitiligo patients were 4.96 times more likely to have depressive symptoms compared to controls. $^{12}$ Psychodermatology is a relatively new area of patient care that focuses on the interaction between the skin and the mind. Thus, in addition to treating the clinical symptoms of vitiligo, dermatologists can also play an important role in helping patients to psychologically adjust to, and accept, their condition. However, an understanding of each vitiligo patient's psychological status is needed so that therapies can be customized to meet the individual needs of individual patients. To date, little is known about depression and QoL among those affected by vitiligo in Thailand. Accordingly, the aim of the study was to investigate the QoL of and the prevalence of depression in Thai vitiligo patients, to evaluate for association between QoL and depression, and to identify factors significantly associated with QoL and depression among Thai people with vitiligo.

\section{Materials and Methods}

\section{Study Design and Sample Size Calculation}

This cross-sectional self-assessment questionnaire-based study was conducted at the phototherapy and vitiligo clinics of the Department of Dermatology, Faculty of Medicine Siriraj Hospital, Mahidol University, Bangkok,
Thailand during May 2019 to October 2019. Siriraj Hospital is Thailand's largest super-tertiary referral center. This study was conducted in accordance with the Declaration of Helsinki and was approved by the Siriraj Institutional Review Board (SIRB) (COA no. Si259/2019). The sample size was calculated using data from a study by Wong and Baba. ${ }^{13}$ Using an estimated standard deviation of 5.17, an allowable error of 1 , an alpha of 0.05 , and a beta of 0.20 , a minimum sample size of 104 patients was calculated.

\section{Demographic and Clinical Characteristics of Vitiligo}

Patients aged $\geq 18$ years with dermatologist-diagnosed vitiligo were recruited. Written informed consent was obtained from all patients willing to join the study. Data, including gender, age, disease duration, skin phototype, occupation, education status, marital status, and thyroid disease, were collected and recorded. Type of vitiligo, current vitiligo activity, extent of lesions, and previous treatment were also documented. Active disease was defined as having one or more of these four clinical signs: confetti-like depigmentation, trichrome lesion, Köebner phenomenon, and/or inflammatory vitiligo.

Extent of vitiligo was assessed using Vitiligo Extent Score (VES). VES is a validated instrument that allows physicians to accurately and easily monitor the affected body surface area in a standardized way. Moreover, VES is considered a user-friendly and time-saving assessment tool. ${ }^{14}$ Vitiligo extent at each affected location is summed to calculate the total percentage of the body surface area that is affected by vitiligo.

\section{Quality of Life and Depression Status}

We used the Dermatology Life Quality Index (DLQI) questionnaire, which was designed by Finlay and Khan in 1994, to assess patient QoL. ${ }^{15}$ The DLQI questionnaire was translated into Thai language and validated by Kulthanan et ali. ${ }^{16}$ The DLQI questionnaire consists of 10 questions with six domains, including symptoms and feeling, daily activities, leisure, work and school, personal relationships, and treatment difficulties. DLQI score is stratified into the five following levels: $0-1=$ no effect, $2-5=$ small effect, $6-10=$ moderate effect, $11-20=$ very large effect, and $21-30=$ extremely large effect. ${ }^{17}$

Presence of depression was assessed using the Patient Health Questionnaire-9 (PHQ-9), which was translated 
into Thai language and validated by Lotrakul et al, ${ }^{18}$ and this assessment was reported to be a brief and user-friendly tool to improve the recognition of depression in primary care. The PHQ-9 is the major depressive disorder module of the full PHQ-9, and all nine components are scored 0 (not at all) to 3 (nearly every day). ${ }^{19}$ Lotrakul et al reported a PHQ-9 score $\geq 9$ to be the optimal cut-off score for diagnosing major depression in the Thai population, with a sensitivity of 0.84 , specificity of 0.77 , positive predictive value of 0.21 , negative predictive value of 0.99 , and positive likelihood ratio of 3.71. All patients were asked to complete both questionnaires by themselves.

\section{Statistical Analysis}

The data were analyzed using SPSS Statistics version 18.0 (SPSS, Inc., Chicago, IL, USA). Quantitative data were described using mean $\pm \mathrm{SD}$, or median and range or IQR. Pearson's correlation coefficient was used to test association between two quantitative variables. Independent $t$-test, chi-squared test, and ANOVA were used to compare continuous and categorical data. Logistic regression analysis was used to calculate the OR to determine which factors may contribute to depression. All $p$-values $<0.05$ were regarded as being statistically significant.

\section{Results}

\section{Demographic and Clinical Characteristics of the Study Population}

A total of 104 individuals with vitiligo were included in this study. Table 1 summarizes the demographic and clinical characteristics of the study population. The mean age of patients was $41.6 \pm 15.9$ years, and most $(70.2 \%)$ of them were female. The mean duration of disease was $8 \pm 10.05$ years. The most common type of vitiligo was nonsegmental vitiligo (76.9\%), and most patients $(56.7 \%)$ had Fitzpatrick skin phototype IV. Almost half of patients (49\%) were suffering from active disease, and $42.3 \%$ of the patients had emergence of new lesions within the last three months. The mean VES was 3.3 \pm 8.47 .

\section{Dermatology Life Quality Index (DLQI)}

The mean DLQI score was 7.46 \pm 6.06 (range: $0-26$ ). The three highest mean DLQI scores were from the questions relating to embarrassment (1.4), social activity (1.11), and clothing (1.01), consecutively (Figure 1). Table 2 shows the results of the analysis to identify factors significantly associated with QoL in vitiligo patients. That analysis
Table I Demographic Data and Clinical Characteristics of Patients with Vitiligo $(n=104)$

\begin{tabular}{|c|c|}
\hline Demographic Data & Total \\
\hline \multicolumn{2}{|l|}{ Gender, n (\%) } \\
\hline Male & $31(29.8)$ \\
\hline Female & $73(70.2)$ \\
\hline Age, mean $\pm S D$, years & $41.55 \pm 15.92$ \\
\hline Duration of disease, median (range), years & $5.00(0.16-60)$ \\
\hline \multicolumn{2}{|l|}{ Marital status, n (\%) } \\
\hline Married & $50(48.1)$ \\
\hline Single & 49 (47.I) \\
\hline Divorced & $5(4.8)$ \\
\hline \multicolumn{2}{|l|}{ Education, n (\%) } \\
\hline Primary & $15(14.4)$ \\
\hline Secondary & $15(14.4)$ \\
\hline Undergraduate & $57(54.8)$ \\
\hline Postgraduate & $16(15.4)$ \\
\hline Doctoral & $\mathrm{I}(\mathrm{I} .0)$ \\
\hline \multicolumn{2}{|l|}{ Occupation, n (\%) } \\
\hline Housewife & $12(\mid I .5)$ \\
\hline Public servant & $17(16.3)$ \\
\hline Business owner & $14(13.5)$ \\
\hline Office worker & $19(18.3)$ \\
\hline Unskilled labor & $14(13.5)$ \\
\hline Unemployed/retired & $9(8.7)$ \\
\hline Student & $19(18.3)$ \\
\hline \multicolumn{2}{|l|}{ Skin phototype, n (\%) } \\
\hline III & $29(27.9)$ \\
\hline IV & $59(56.7)$ \\
\hline V & $16(15.4)$ \\
\hline \multicolumn{2}{|l|}{ Thyroid diseases, n (\%) } \\
\hline Yes & $9(8.7)$ \\
\hline No & $95(91.3)$ \\
\hline \multicolumn{2}{|l|}{ Type, n (\%) } \\
\hline Segmental & $24(23.1)$ \\
\hline Nonsegmental & $80(76.9)$ \\
\hline \multicolumn{2}{|l|}{ Disease activity, n (\%) } \\
\hline Stable & $53(51.0)$ \\
\hline Active & $51(49.0)$ \\
\hline \multicolumn{2}{|l|}{ Poliosis, n (\%) } \\
\hline Yes & $12(1 \mathrm{I} .5)$ \\
\hline No & $92(88.5)$ \\
\hline VES, median (range) & $0.69(0.01-58.37)$ \\
\hline \multicolumn{2}{|l|}{ Previous treatment, $\mathrm{n}(\%)$} \\
\hline Topical medication & $100(96.2)$ \\
\hline Systemic medication & $31(29.8)$ \\
\hline Phototherapy & $85(81.7)$ \\
\hline
\end{tabular}

(Continued) 
Table I (Continued).

\begin{tabular}{|c|c|}
\hline Demographic Data & Total \\
\hline Duration of treatment, median (range), month & $19(0-720)$ \\
\hline DLQI, mean $\pm S D$ & $7.46 \pm 6.06$ \\
\hline DLQI, median (range) & $6(0-26)$ \\
\hline PHQ-9, mean \pm SD & $4.09 \pm 4.49$ \\
\hline PHQ-9, median (range) & $3(0-25)$ \\
\hline
\end{tabular}

Abbreviations: DLQI, Dermatology Life Quality Index; VES, Vitiligo Extent Score; PHQ-9, Patient Health Questionnaire-9.

revealed skin phototype IV compared to phototype III, active disease, new lesions appearing within the last three months, and lesions involving the upper extremities (excluding bony prominences) to be significantly associated with QoL. Regarding skin phototype, we found no significant difference between skin phototype $\mathrm{V}$ and other skin phototypes. Importantly, a high DLQI score was strongly significant associated with depressive status reflected in PHQ-9 $\geq 9$. We found no significant difference in higher DLQI score between women and men, between the working age group (age 30-59 years) compared to other age groups, employed patients compared to unemployed patients, location other than upper extremities, longer treatment duration, or VES extent.

\section{Depression}

The mean PHQ-9 score was 4.09 \pm 4.49 (range: 0-25). Fourteen patients (13.5\%) had PHQ-9 $\geq 9,65$ cases had a PHQ-9 score of $0-4$, and 25 cases had a score of 5-8 (mild) (Figure 2). When we compared the DLQI score between the depressive group (PHQ-9 $\geq 9$ ) and the PHQ$9<9$ group, the three highest scores in the depressive group were the scores for social activities, embarrassment, clothing, shopping and homecare (Figure 1). This finding helps to explain the moderate correlation observed between the DLQI score and the PHQ-9 score (Pearson's correlation coefficient: 0.524, $p<0.001$ ) (Figure 3).

Table 3 summarizes the factors significantly associated with depression in vitiligo patients. We found a significantly higher prevalence of depression in employed individuals than students, unemployed, or retired people $(p=0.046)$. Depression was considerably more frequent in patients with active vitiligo than those with stable disease. In addition, individuals with new lesions appearing within the last three months were significantly more likely to be depressed than those with no new lesions ( $p=0.018$ ), and logistic regression analysis showed patients with new lesions to be 4.12 times more likely to show depression compared to those without new lesions (OR: $4.12,95 \% \mathrm{CI}$ : $1.20-14.16 ; p=0.025$ ).

There were no statistically significant differences in PHQ9 score for gender, age group, education level, skin phototype, or type of vitiligo. Nonetheless, depression was not associated with involved locations, treatment duration or VES.

\section{Discussion}

Current pathogenesis of vitiligo is complex, mainly involved heat shock protein 70, interferon-gamma, JAK-STAT, CXCL10, effector and memory CD8 ${ }^{+} \mathrm{T}$ cell lymphocyte. ${ }^{20}$ Treatment of vitiligo included topical corticosteroid, calcineurin inhibitors, systemic immunosuppressants, UVB



Figure I Dermatology Life Quality Index (DLQI) score for each of the 10 questions compared between the Patient Health Questionnaire (PHQ)- $9<9$ group and the PHQ$9 \geq 9$ group. 
Table 2 Factors Associated with Quality of Life in Patients with Vitiligo

\begin{tabular}{|c|c|c|}
\hline Factors & $\begin{array}{l}\text { Mean DLQI } \\
\text { 土SD }\end{array}$ & $p$ value \\
\hline \multicolumn{3}{|l|}{ Gender } \\
\hline Male $(n=3 I)$ & $6.45 \pm 6.10$ & 0.270 \\
\hline Female $(n=73)$ & $7.89 \pm 6.04$ & \\
\hline \multicolumn{3}{|l|}{ Age (years) } \\
\hline$<30(n=28)$ & $6.79 \pm 4.92$ & 0.133 \\
\hline $30-59(n=63)$ & $8.10 \pm 6.59$ & \\
\hline$\geq 60(n=13)$ & $5.85 \pm 5.57$ & \\
\hline \multicolumn{3}{|l|}{ Education } \\
\hline Below undergraduate $(n=30)$ & $6.73 \pm 5.07$ & 0.438 \\
\hline Undergraduate and above $(n=74)$ & $7.76 \pm 6.43$ & \\
\hline \multicolumn{3}{|l|}{ Occupation } \\
\hline $\begin{array}{l}\text { Unemployed/retired/students } \\
(\mathrm{n}=40)\end{array}$ & $6.15 \pm 5.26$ & 0.081 \\
\hline Employed $(n=64)$ & $8.28 \pm 6.42$ & \\
\hline \multicolumn{3}{|l|}{ Skin phototype } \\
\hline III $(n=29)$ & $5.38 \pm 4.31$ & $0.032 *$ \\
\hline IV $(n=59)$ & $8.92 \pm 6.55$ & \\
\hline$V(n=16)$ & $5.88 \pm 5.69$ & \\
\hline \multicolumn{3}{|l|}{ Types of vitiligo } \\
\hline Segmental $(n=24)$ & $8.38 \pm 7.13$ & 0.403 \\
\hline Non-segmental $(n=80)$ & $7.19 \pm 5.73$ & \\
\hline \multicolumn{3}{|l|}{ Disease activity } \\
\hline Stable $(n=53)$ & $6.21 \pm 5.54$ & $0.03 I^{*}$ \\
\hline Active $(n=5 I)$ & $8.76 \pm 6.36$ & \\
\hline \multicolumn{3}{|l|}{ New lesion in three months } \\
\hline Yes $(n=44)$ & $9.09 \pm 6.36$ & $0.018^{*}$ \\
\hline No $(n=60)$ & $6.27 \pm 5.59$ & \\
\hline \multicolumn{3}{|l|}{ Involved area } \\
\hline \multicolumn{3}{|l|}{ Head and neck } \\
\hline Yes $(n=75)$ & $7.59 \pm 6.11$ & 0.737 \\
\hline No $(n=29)$ & $7.14 \pm 6.03$ & \\
\hline \multicolumn{3}{|l|}{ Trunk } \\
\hline Yes $(n=60)$ & $8.12 \pm 6.07$ & 0.200 \\
\hline No $(n=44)$ & $6.57 \pm 6.01$ & \\
\hline \multicolumn{3}{|l|}{ Acral } \\
\hline Yes $(n=68)$ & $7.78 \pm 5.83$ & 0.465 \\
\hline No $(n=36)$ & $6.86 \pm 6.52$ & \\
\hline \multicolumn{3}{|l|}{ Upper extremities } \\
\hline Yes $(n=32)$ & $9.53 \pm 6.53$ & $0.020 *$ \\
\hline No $(n=72)$ & $6.54 \pm 5.65$ & \\
\hline \multicolumn{3}{|l|}{ Lower extremities } \\
\hline Yes $(n=34)$ & $7.74 \pm 6.06$ & 0.750 \\
\hline No $(n=70)$ & $7.33 \pm 6.10$ & \\
\hline
\end{tabular}

(Continued)
Table 2 (Continued).

\begin{tabular}{|l|l|l|}
\hline Factors & $\begin{array}{l}\text { Mean DLQI } \\
\pm \text { SD }\end{array}$ & p value \\
\hline $\begin{array}{l}\text { Bony prominence } \\
\text { Yes ( } n=26)\end{array}$ & $8.15 \pm 5.64$ & 0.504 \\
No $(n=78)$ & $7.23 \pm 6.22$ & \\
\hline $\begin{array}{l}\text { Mucosal } \\
\text { Yes }(n=29)\end{array}$ & & \\
No $(n=75)$ & $7.75 \pm 6.33$ & 0.443 \\
\hline $\begin{array}{l}\text { Treatment duration } \\
\text { Less than one year }(n=30)\end{array}$ & $8.30 \pm 7.07$ & 0.668 \\
I-2 years ( $n=42)$ & $7.19 \pm 5.99$ & \\
More than two years $(n=32)$ & $7.03 \pm 5.19$ & \\
\hline VES & & \\
VES $<5$ ( $n=89)$ & $7.27 \pm 6.15$ & 0.434 \\
VES $\geq 5$ ( $n=15)$ & $8.60 \pm 5.55$ & \\
\hline PHQ-9 (Depression; PHQ-9 $\geq 9)$ & & \\
PHQ-9 $<9(n=90)$ & $6.29 \pm 5.22$ & \\
PHQ-9 $\geq 9(n=14)$ & $15.00 \pm 5.83$ & \\
\hline
\end{tabular}

Note: *Significant variables.

Abbreviations: DLQI, Dermatology Life Quality Index; VES, Vitiligo Extent Score; PHQ-9, Patient Health Questionnaire-9.

phototherapy and surgery. ${ }^{21-23}$ Novel targeted therapy focused on JAK inhibitor with some success. ${ }^{21}$ However, no current treatment can cure the disease. After treatment discontinuation, vitiligo lesions frequently return, supporting the hypothesis of autoimmune memory at vitiligo location. ${ }^{24}$ Disease stabilization and stimulation of repigmentation are the main concepts of treatment and should be performed as early as first lesions appear. Prognosis is correlated with disease location and onset of treatment. Due to the unpredictable clinical course and long-standing treatment, vitiligo undoubtedly affects the psychosocial impact state and QoL.

\section{Quality of Life}

Earlier studies have reported mean DLQI scores of vitiligo ranging from 1.82 to $15 .{ }^{4}$ Our study showed mean DLQI score of 7.46 which represented a moderate effect on patients' QoL. This was similar to QoL in studies by Dolatshahi et al and Wang et al. ${ }^{25,26}$ The three main effects were embarrassment, social activities, and choice of clothing which were similar to previous studies. ${ }^{7,27}$ When compared to other dermatologic conditions in Thailand, vitiligo DLQI is higher than fungal 


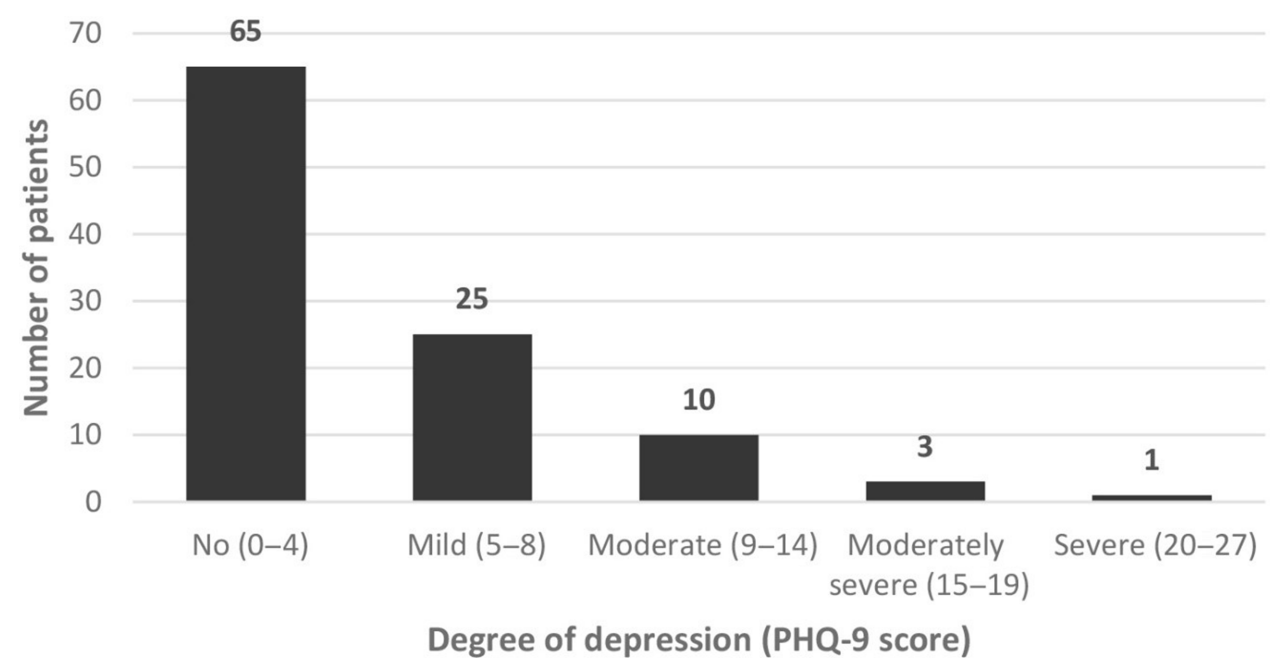

Figure 2 Severity of depression according to Patient Health Questionnaire (PHQ)-9 scoring among Thai vitiligo patients.

infection $(6.5)^{28}$ but lower than seborrheic dermatitis $(8.1)^{29}$ and acne (10.6). ${ }^{28}$

Amer and Gao demonstrated that individuals with vitiligo in Asian countries such as India and Saudi Arabia seemed to have a higher DLQI score compared to those in Caucasian countries due to darker skin phototypes and differences in culture. ${ }^{4}$ Our study found individuals with skin phototype IV had significantly higher DLQI than those with phototype III $(p=0.032)$, but lack of significant differences between skin phototype V and type III and IV. Dolatshahi et al, found that patients with skin phototype $\mathrm{V}$ had significantly poorer QoL than in those other types $(p<0.001)$ due to the contrast between vitiligo lesions and darker skin. ${ }^{25}$ These can be explained from the small number of our patients with skin phototype $\mathrm{V}$.

Active disease is clinically defined as rapid spreading of news lesions, confetti-like depigmentation, trichrome and Köebner phenomenon. Active vitiligo should receive prompt and aggressive treatment to halt and prevent further spreading of depigmentation. This mainly included immunosuppressants and phototherapy. Our study demonstrated individuals with active vitiligo and patients who developed new lesions within the last three months had significantly higher DLQI score denoting a higher impact on their QoL than those with stable vitiligo and no new lesions. These were also observed by Karelson et al, in which the DLQI score was significantly associated with active stage of the disease $(p=0.006){ }^{30}$ The rapid spreading of disease can turn to widespread lesions and prognosis is unpredictable. As a result, the activity of the disease greatly impaired QoL.
Based on the location, our study showed that individuals with vitiligo lesions on upper extremities, which are visible parts, were significantly associated with poorer QoL Previous studies supported the concept of lesions occurring on visible or exposed regions of the body having significantly higher DLQI scores than those without lesions. ${ }^{13,27}$ In addition, Silverberg and Silverberg's study showed that lesions on the arms were significantly associated with self-consciousness about vitiligo, ${ }^{7}$ and therefore visible lesions could affect patients' confidence and disturb QoL.

Our study showed that vitiligo patients with depression had significantly higher DLQI scores than those without depression $(p<0.001)$. This relationship was also observed by Chan et al, where vitiligo patients with a DLQI score of six and above were 4.88 times more likely to develop depression compared to those with a score of $0-5 .{ }^{31}$ In addition, we also found that the DLQI score displayed moderate correlation with the PHQ-9 score. QoL impairment would probably affect patients' mood and eventually they would develop depressive symptoms.

We found a trend of QoL impairment in female than male patients, although lack of significant effect, similar to previous studies. ${ }^{13,25}$ Women have more cosmetic concerns than men, regardless of age groups, socioeconomic and living status, and therefore seek more treatment. ${ }^{32}$

Our study also showed a trend of higher mean DLQI score among individuals who were working than those who were students, unemployed or had retired but we did not find statistical significance between the two groups. However, Wong and Baba's study revealed that patients who had jobs 


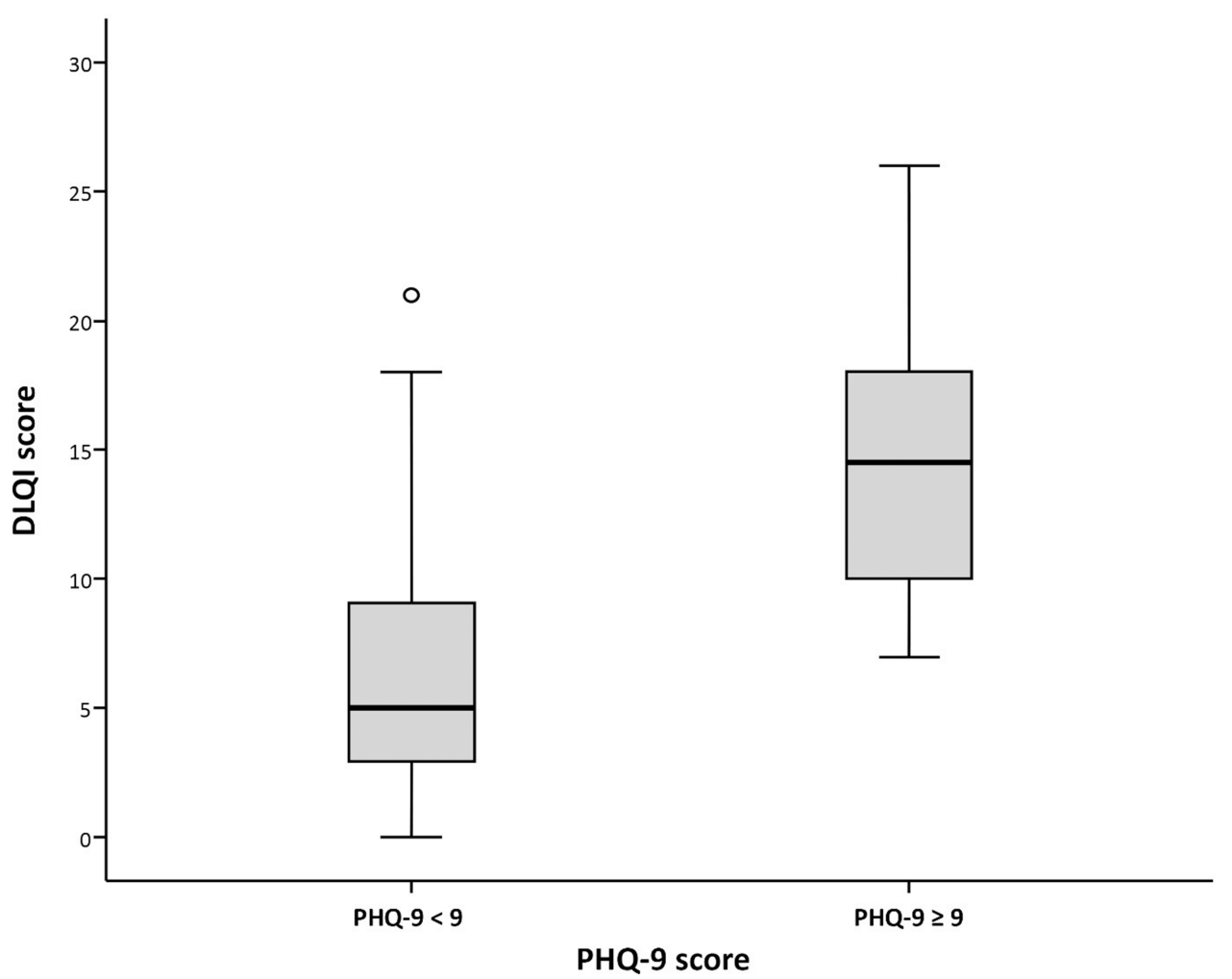

Figure 3 Box plot showing Patient Health Questionnaire (PHQ)-9 scoring compared between the PHQ $<9$ group and the PHQ-9 $\geq 9$ group relative to Dermatology Life Quality Index (DLQI) score.

Notes: The o symbol represents score in one case of patient that is not in the bar range.

had significantly higher DLQI scores compared to those who were retired. People who were employed or had to go out for work and meet other people might feel more embarrassed, therefore, resulting in reduction of QoL. ${ }^{13}$ Regarding age groups, age 30-59 years which was a working age group also seemed to have higher DLQI scores compared to other groups (Table 2).

\section{Depression}

The prevalence of depression among our vitiligo patients based on PHQ-9 $\geq 9$ was $13.5 \%$, which was lower than earlier studies. ${ }^{33-35}$ Most of our patients had none or mild depressive symptoms similar to a study from Iran. ${ }^{11}$ Prevalence of depression and depressive symptoms varies among the studies depending on the diagnostic criteria or instruments used. $^{12}$ Reported screening instruments included Hamilton Depression Rating scale (HDRS) and Beck Depression Inventory (BDI). ${ }^{12}$ However, Dabas et al, by using PHQ-9, found that the prevalence of depression among their vitiligo population in India was $27.4 \%$ which was higher than that in our study. ${ }^{36}$ The reason for this could be that vitiligo lesions might be more noticeable on darker skin color. It should be noted that the sensitivity of PHQ-9 is high but the positive predictive value of PHQ-9 is low. Therefore, clinical assessment by psychiatrists is recommended.

We observed that depression was significantly associated with working status of the patients $(p=0.046)$ and significantly associated with developing new lesions with the last three months $(p=0.018)$. Individuals with new lesions developing in three months were 4.12 times more likely to have depression compared to those without new lesions (OR: 4.12, 95\%CI: 1.20-14.16; $p=0.025$ ). This could be explained by the rapid spreading and the patients might feel more concerned about the occurrence of new lesions since the disease has no cure.

According to the earlier meta-analysis, the prevalence of depression in women with vitiligo was significantly higher than that in men. ${ }^{12}$ However, we found no statistically significant differences in depression between genders, age groups, skin phototypes, types of vitiligo and involved areas.

We found a significant correlation between DLQI score and PHQ-9 in vitiligo. Patients whose QoL was affected had depressive symptoms and vice versa. These were similar to 
Table 3 Factors Associated with Depression Among Patients with Vitiligo

\begin{tabular}{|c|c|c|c|}
\hline Factors & $\begin{array}{l}\text { Number of } \\
\text { Cases PHQ-9 } \\
<9\end{array}$ & $\begin{array}{l}\text { Number of } \\
\text { Cases PHQ-9 } \\
\geq 9\end{array}$ & $\mathrm{p}$ value \\
\hline \multicolumn{4}{|l|}{ Gender } \\
\hline Male & 27 & 4 & 1.000 \\
\hline Female & 63 & 10 & \\
\hline \multicolumn{4}{|l|}{ Age group } \\
\hline Age $<30$ & 26 & 2 & 0.097 \\
\hline Age $30-59$ & 51 & 12 & \\
\hline Age $\geq 60$ & 13 & 0 & \\
\hline \multicolumn{4}{|l|}{ Education } \\
\hline Below undergraduate & 27 & 3 & 0.752 \\
\hline $\begin{array}{l}\text { Undergraduate and } \\
\text { above }\end{array}$ & 63 & 11 & \\
\hline \multicolumn{4}{|l|}{ Occupation } \\
\hline $\begin{array}{l}\text { Unemployed/retired/ } \\
\text { students }\end{array}$ & 38 & 2 & $0.046 *$ \\
\hline Employed & 52 & 12 & \\
\hline \multicolumn{4}{|l|}{ Skin phototype } \\
\hline III & 27 & 2 & 0.234 \\
\hline IV & 51 & 8 & \\
\hline v & 12 & 4 & \\
\hline \multicolumn{4}{|l|}{ Types of vitiligo } \\
\hline Segmental & 20 & 4 & 0.733 \\
\hline Nonsegmental & 70 & 10 & \\
\hline \multicolumn{4}{|l|}{ Disease progression } \\
\hline Stable & 49 & 4 & 0.072 \\
\hline Active & 41 & 10 & \\
\hline \multicolumn{4}{|l|}{ New lesion in three months } \\
\hline Yes & 34 & 10 & $0.018^{*}$ \\
\hline No & 56 & 4 & \\
\hline \multicolumn{4}{|l|}{ Involved area } \\
\hline \multicolumn{4}{|l|}{ Head and neck } \\
\hline Yes & 63 & 12 & 0.340 \\
\hline No & 27 & 2 & \\
\hline \multicolumn{4}{|l|}{ Trunk } \\
\hline Yes & 49 & 11 & 0.089 \\
\hline No & 41 & 3 & \\
\hline \multicolumn{4}{|l|}{ Acral } \\
\hline Yes & 58 & 10 & 0.766 \\
\hline No & 32 & 4 & \\
\hline \multicolumn{4}{|l|}{ Upper extremities } \\
\hline Yes & 28 & 4 & 1.000 \\
\hline No & 62 & 10 & \\
\hline \multicolumn{4}{|l|}{ Lower extremities } \\
\hline Yes & 31 & 3 & 0.541 \\
\hline No & 59 & 11 & \\
\hline \multicolumn{4}{|l|}{ Bony prominence } \\
\hline Yes & 24 & 2 & 0.509 \\
\hline No & 66 & 12 & \\
\hline
\end{tabular}

(Continued)
Table 3 (Continued).

\begin{tabular}{|l|l|l|l|}
\hline Factors & $\begin{array}{l}\text { Number of } \\
\text { Cases PHQ-9 } \\
<9\end{array}$ & $\begin{array}{l}\text { Number of } \\
\text { Cases PHQ-9 } \\
\geq 9\end{array}$ & p value \\
\hline $\begin{array}{l}\text { Mucosal } \\
\text { Yes }\end{array}$ & 24 & 5 & 0.527 \\
No & 66 & 9 & \\
\hline $\begin{array}{l}\text { Treatment duration } \\
\text { Less than one year }\end{array}$ & 27 & 3 & 0.388 \\
I-2 years & 34 & 8 & \\
More than two years & 9 & 3 & 0.405 \\
\hline VES & & 13 & \\
VES $<5$ & 76 & 1 & \\
VES $\geq 5$ & 14 & & \\
\hline
\end{tabular}

Note: *Significant variables.

Abbreviations: PHQ-9, Patient Health Questionnaire-9; VES, Vitiligo Extent Score.

previous studies. ${ }^{36,37}$ Therefore dermatologists should be concerned and keep in mind depressive symptoms when they detect and recognize the high DLQI score. Coping with depressive symptoms could improve QoL.

Nowadays, psychodermatology and liaison psychiatry clinics play an important role in treating and supporting patients with chronic intractable dermatologic conditions, including vitiligo. The multidisciplinary approach provides the patients with an individualized holistic care with the cooperation of dermatologist, psychiatrist and other specialized personnel. In addition to treating preexisting psychiatric diseases, psychiatrists also play a critical role in early detection of mild psychiatric conditions,especially depression. They can provide early interventions to prevent the progression of mild conditions to serious psychiatric disorders.

Few studies focused on treatment for depression in individuals with vitiligo. Papadopoulos et al found that cognitive behavioral and person-centered therapies in patients with vitiligo can significantly improve patients' ability to cope with the disease assessed by the General Health Questionnaire. ${ }^{38}$ Thus, early psychological intervention might be helpful to prevent depression and enhance patients' coping mechanism to improve their QoL.

\section{Limitations}

This study was conducted in a single tertiary-care hospital which might not represent all Thai individuals with vitiligo or might not be generalizable to other countries. Although PHQ-9 is the standard measurement for screening of depression, its limitation is that it is a self-rated questionnaire. 
Additional clinical information, eg, patient's function, effects of medication, illness, and psychiatric evaluation are recommended for definite diagnosis and comprehensive evaluation. Moreover, patients were informed that they were tested for depression and QoL before answering the questionnaire and thus their responses may be biased.

\section{Conclusion}

Vitiligo showed moderate QoL impairment in the Thai population and moderate prevalence of depression. These two factors are well correlated. Development of new lesions, active disease, dark skin phototype (IV) and lesions on upper extremities had significant effects on QoL. In addition, new vitiligo lesions and employed workers had risks of depressive symptoms. Vitiligo patients who were working or in active stage of the disease had a significant impairment in QoL and were associated with depression. These patients might need an appropriate health-care consultation, more aggressive interventions to halt disease progression and regular screening for depression. Liaison psychiatry clinics can play an important role in supporting patients with vitiligo and dermatologist should take part in this psychosocial issue to provide a holistic approach for this chronic, visible, and unpredictable condition.

\section{Acknowledgments}

The authors gratefully acknowledge the patients who participated in this study, and Mr Suthipol Udompunthurak of the Research Group and Research Network Division, Research Department, Faculty of Medicine Siriraj Hospital, Mahidol University for assistance with statistical analysis.

\section{Funding}

This was an unfunded study.

\section{Disclosure}

The authors report no conflicts of interest in this work.

\section{References}

1. Kruger C, Schallreuter KU. A review of the worldwide prevalence of vitiligo in children/adolescents and adults. Int $J$ Dermatol. 2012;51:1206-1212. doi:10.1111/j.1365-4632.2011.05377.x

2. Rodrigues M, Ezzedine K, Hamzavi I, Pandya AG, Harris JE. New discoveries in the pathogenesis and classification of vitiligo. $J \mathrm{Am}$ Acad Dermatol. 2017;77:1-13. doi:10.1016/j.jaad.2016.10.048

3. Bú EAD, Alexandre M, Scardua A, Araújo C. Vitiligo as a psychosocial disease: apprehensions of patients imprinted by the white. Interface-Comunicação, Saúde, Educação. 2017;22:481-492. doi:10.1590/1807-57622016.0925
4. Amer AA, Gao XH. Quality of life in patients with vitiligo: an analysis of the dermatology life quality index outcome over the past two decades. Int J Dermatol. 2016;55:608-614. doi:10.1111/ ijd.13198

5. Parsad D, Pandhi R, Dogra S, Kanwar AJ, Kumar B. Dermatology life quality index score in vitiligo and its impact on the treatment outcome. Br J Dermatol. 2003;148:373-374. doi:10.1046/j.13652133.2003.05097_9.x

6. Bin Saif GA, Al-Balbeesi AO, Binshabaib R, et al. Quality of life in family members of vitiligo patients: a questionnaire study in Saudi Arabia. Am J Clin Dermatol. 2013;14:489-495. doi:10.1007/s40257013-0037-5

7. Silverberg JI, Silverberg NB. Association between vitiligo extent and distribution and quality-of-life impairment. JAMA Dermatol. 2013;149:159-164. doi:10.1001/jamadermatol.2013.927

8. Ongenae K, Van Geel N, De Schepper S, Naeyaert JM. Effect of vitiligo on self-reported health-related quality of life. $\mathrm{Br} J$ Dermatol. 2005;152:1165-1172. doi:10.1111/j.1365-2133.2005.06456.x

9. Ongenae K, Beelaert L, van Geel N, Naeyaert JM. Psychosocial effects of vitiligo. J Eur Acad Dermatol Venereol. 2006;20:1-8. doi:10.1111/j.1468-3083.2005.01369.x

10. Osinubi O, Grainge MJ, Hong L, et al. The prevalence of psychological comorbidity in people with vitiligo: a systematic review and meta-analysis. $\mathrm{Br} J$ Dermatol. 2018;178:863-878. doi:10.1111/ bjd. 16049

11. Hamidizadeh N, Ranjbar S, Ghanizadeh A, Parvizi MM, Jafari P, Handjani F. Evaluating prevalence of depression, anxiety and hopelessness in patients with Vitiligo on an Iranian population. Health Qual Life Outcomes. 2020;18:20. doi:10.1186/s12955-020-1278-7

12. Wang G, Qiu D, Yang H, Liu W. The prevalence and odds of depression in patients with vitiligo: a meta-analysis. $J$ Eur Acad Dermatol Venereol. 2018;32:1343-1351. doi:10.1111/jdv.14739

13. Wong SM, Baba R. Quality of life among Malaysian patients with vitiligo. Int $J$ Dermatol. 2012;51:158-161. doi:10.1111/j.13654632.2011.04932.x

14. van Geel N, Lommerts J, Bekkenk M, et al. Development and validation of the Vitiligo Extent Score (VES): an International Collaborative Initiative. $J$ Invest Dermatol. 2016;136:978-984. doi:10.1016/j.jid.2015.12.040

15. Finlay AY, Khan GK. Dermatology Life Quality Index (DLQI)-a simple practical measure for routine clinical use. Clin Exp Dermatol. 1994;19:210-216. doi:10.1111/j.1365-2230.1994.tb01167. $\mathrm{x}$

16. Kulthanan K, Wanitphakdeedecha R, Chantharujikaphong S. The validity and reliability of Dermatology Life Quality Index (DLQI) in Thais. Thai J Dermatol. 2004;20:113-123.

17. Hongbo Y, Thomas CL, Harrison MA, Salek MS, Finlay AY. Translating the science of quality of life into practice: what do dermatology life quality index scores mean? J Invest Dermatol. 2005;125:659-664. doi:10.1111/j.0022-202X.2005.23621.x

18. Lotrakul M, Sumrithe S, Saipanish R. Reliability and validity of the Thai version of the PHQ-9. BMC Psychiatry. 2008;8:46. doi:10.1186/ 1471-244X-8-46

19. Kroenke K, Spitzer RL, Williams JB. The PHQ-9: validity of a brief depression severity measure. J Gen Intern Med. 2001;16:606-613. doi:10.1046/j.1525-1497.2001.016009606.x

20. Lyons AB, Ghia D, Abdallah M, et al. Proceeding Report of the Second Vitiligo International Symposium-November 9- 10, 2018, Detroit, Michigan, USA. Pigment Cell Melanoma Res. 2020;33 (4):637-641. doi:10.1111/pcmr.12867

21. Rodrigues M, Ezzedine K, Hamzavi I, Pandya AG, Harris JE. Current and emerging treatments for vitiligo. $J$ Am Acad Dermatol. 2017;77:17-29. doi:10.1016/j.jaad.2016.11.010

22. Silpa-Archa N, Lim HW, Wongpraparut C. Excimer laser in vitiligo: where there is light, there is hope. Br J Dermatol. 2019;181:21-22. doi:10.1111/bjd.18101 
23. Silpa-Archa N, Weerasubpong P, Junsuwan N, Yothachai P, Supapueng O, Wongpraparut C. Treatment outcome and persistence of repigmentation from narrow-band ultraviolet B phototherapy in vitiligo. J Dermatolog Treat. 2019;30:691-696. doi:10.1080/ 09546634.2018.1544409

24. Riding RL, Harris JE. The role of memory CD8(+) T Cells in Vitiligo. J Immunol. 2019;203:11-19. doi:10.4049/jimmunol.1900027

25. Dolatshahi M, Ghazi P, Feizy V, Hemami MR. Life quality assessment among patients with vitiligo: comparison of married and single patients in Iran. Indian J Dermatol Venereol Leprol. 2008;74:700. doi:10.4103/0378-6323.45141

26. Wang KY, Wang KH, Zhang ZP. Health-related quality of life and marital quality of vitiligo patients in China. J Eur Acad Dermatol Venereol. 2011;25:429-435. doi:10.1111/j.1468-3083.2010.03808.x

27. Radtke MA, Schafer I, Gajur A, Langenbruch A, Augustin M. Willingness-to-pay and quality of life in patients with vitiligo. $\mathrm{Br}$ J Dermatol. 2009;161:134-139. doi:10.1111/j.1365-2133.2009.09091.x

28. Kulthanan K, Jiamton S, Wanitphakdeedecha R, Chantharujikaphong $\mathrm{S}$. The validity and reliability of the Dermatology Life Quality Index (DLQI) in Thais. Thai J Dermatol. 2004;20:110-123.

29. Araya M, Kulthanan K, Jiamton S. Clinical characteristics and quality of life of seborrheic dermatitis patients in a tropical country. Indian J Dermatol. 2015;60:519. doi:10.4103/0019-5154.164410

30. Karelson M, Silm H, Kingo K. Quality of life and emotional state in vitiligo in an Estonian sample: comparison with psoriasis and healthy controls. Acta Derm Venereol. 2013;93:446-450. doi:10.2340/ 00015555-1520

31. Chan MF, Chua TL, Goh BK, Aw CW, Thng TG, Lee SM. Investigating factors associated with depression of vitiligo patients in Singapore. J Clin Nurs. 2012;21:1614-1621. doi:10.1111/j.13652702.2011.03777.x
32. Harris DL, Carr AT. Prevalence of concern about physical appearance in the general population. Br J Plast Surg. 2001;54:223-226. doi:10.1054/bjps.2001.3550

33. Sangma LN, Nath J, Bhagabati D. Quality of life and psychological morbidity in vitiligo patients: a study in a teaching hospital from north-East India. Indian J Dermatol. 2015;60:142-146. doi:10.4103/ 0019-5154.152508

34. Sampogna F, Raskovic D, Guerra L, et al. Identification of categories at risk for high quality of life impairment in patients with vitiligo. $\mathrm{Br}$ J Dermatol. 2008;159:351-359. doi:10.1111/j.1365-2133.2008.08678.x

35. Choi S, Kim DY, Whang SH, Lee JH, Hann SK, Shin YJ. Quality of life and psychological adaptation of Korean adolescents with vitiligo. J Eur Acad Dermatol Venereol. 2010;24:524-529. doi:10.1111/ j.1468-3083.2009.03452.x

36. Dabas G, Vinay K, Parsad D, Kumar A, Kumaran MS. Psychological disturbances in patients with pigmentary disorders: a cross-sectional study. J Eur Acad Dermatol Venereol. 2020;34:392-399. doi:10.1111/ jdv. 15987

37. Satti MZ, Arshad D, Javed H, et al. Uremic pruritus: prevalence and impact on quality of life and depressive symptoms in hemodialysis patients. Cureus. 2019;11:e5178.

38. Papadopoulos L, Cj W, Anthis L. Living with Vitiligo: a controlled investigation into the effects of group cognitive-behavioural and person-centred therapies. Dermatol Psychosom. 2004;5:172-177. doi: $10.1159 / 000083091$

\section{Publish your work in this journal}

Clinical, Cosmetic and Investigational Dermatology is an international, peer-reviewed, open access, online journal that focuses on the latest clinical and experimental research in all aspects of skin disease and cosmetic interventions. This journal is indexed on CAS.
The manuscript management system is completely online and includes a very quick and fair peer-review system, which is all easy to use. Visit http://www.dovepress.com/testimonials.php to read real quotes from published authors. 